\title{
DIMENSIONS OF STUDENTS' ENGAGEMENT AND SELF-INSIGHT IN UPPER SECONDARY EDUCATION
}

\author{
Peter Grandits \\ Faculty of Education, University of Ljubljana (Slovenia)
}

\begin{abstract}
The aim of this study was to analyse the dimensionality and reliability of an instrument capable of measuring readers' engagement and self-insight in literature education. A self-report questionnaire was administered to upper secondary grammar school students in three Austrian regions $(\mathrm{n}=417)$. Principal axis factoring with Promax rotation was conducted. As the number of factors to be retained was ambiguous, various models were tested. Finally, I arrived at an eight-factor solution which fulfilled the most relevant theoretical and statistical criteria for this study. The factors Insight and Self-perceptual depth are considered to be forms of self-insight, the factors Cognitive Perspective-taking, Identification, Narrative Presence, Pre-enactive Empathy, Realism, and Self-implicating Givenness constitute interrelated modes of engagement. The Cronbach alpha values for the subscales generated by PAF indicated adequate internal consistency. Limitations and implications are discussed.
\end{abstract}

Keywords: Factor analysis, literature education, scientific study of literature, narrative engagement, self-insight.

\section{Introduction}

Empirical research on the assessment of pedagogical interventions in the field of literature education presupposes the availability of reliable and valid instruments to measure students' responses to literary texts. This study aimed to determine the dimensionality and internal consistency of existing measures in order to provide a psychometrically sound post facto instrument that is capable of testing the effects of instructional interventions on high school students.

Miall highlights the need to examine literature education empirically in order to improve the practices in the literature classroom (Miall, 2011). According to Fialho, Zyngier and Burke (2016), scientific study of literature education has mainly been conducted in three lines of research: 1. reading experience (Fialho, Zyngier \& Miall, 2011; Janssen \& Rijlaarsdam, 1995; Miall, 2006; van Schooten, Ootsdam \& de Glopper, 2001), 2. knowledge that informs readers in their responses (Andriga, 1996; Janssen et al, 2012), and 3. growth of literary expertise (Peskin, 2010; van Schooten \& de Glopper, 2003). The author concludes that very few efforts have been expended to produce evidence-based theories and to test their educational relevance.

With a few exceptions (e.g. Fialho, Zyngier \& Miall, 2011; Shrijvers et al, 2019), instructional interventions in the field of literature education were not subjected to empirical testing. In order to be able to empirically verify impacts of instructional interventions on high school students' engagement and self-insight, the psychometric properties of given subscales were tested in classes 11 and 12 of grammar schools across Austria. Whereas transactional modes of engagement (Rosenblatt, 1995) are supposed to indicate students' level of agency, self-insight addresses shifts in self-perception and self-understanding resulting from the reading and teaching of literary texts.

To analyse engagement, the Empathy subscale from the LRQ (Miall \& Kuiken, 1995) was applied. It measures projective identification with fictional characters and reflects the extended presence of these characters with the reader. The Emotional Engagement and Narrative Presence subscales were included from the Narrative Engagement Scale (Busselle \& Bilandzic, 2009). They measure the feeling for and with characters and the sensation that the reader has left the actual world and entered the diegesis. From the ASQ (Kuiken \& Douglas, 2017), Expressive Enactment (mini-scales: 1. Peri-personal Space, 2. Pre-enactive Empathy, 3. Self-implicating Givenness) and Integrative Comprehension (mini-scales: 1. Extra-personal Space, 2. Cognitive Perspective-taking, 3a. Realistic Conduct, 3b. Affective Realism) subscales were selected. The first set of mini-scales measures processes of transportation (Cf. Narrative Presence), the second set different modes of empathy, and the third set associations readers find between the text and the self or the real world. 
Two subscales are used to explore self-insight: a. Insight from the LRQ (s.a.), and b. Self-perceptual depth from the EQ (Kuiken, Campbell \& Sopcak, 2012). Insight focuses on shifts in self-understanding whereas Self-perceptual Depth examines changes in self-perception.

In the following study, the question of which dimensions of engagement and self-insight can be extracted from the data gathered from Austrian students in uppers secondary education will be addressed.

\section{Methods}

\subsection{Participants}

The sample comprised 417 Austrian students attending grades 11 and 12 of public grammar schools. 225 were female (54.0\%), 192 male (46.0\%). The sample was evenly distributed between students from rural $(\mathrm{n}=211)$ and urban areas $(\mathrm{n}=206)$.

\subsection{Procedure} school year.

The items of the instrument were translated into German and administered during the 2019/20

To obtain a representative sample of students in grades 11 and 12, we drew a sample from the population of 135 grammar schools in the regions of Burgenland (96 students), Carinthia (115 students) and Vienna (206 students). Representatives of the regional education authorities randomly selected schools and classes to participate in the given validation study. As a consequence, students were not selected on their competence in literature education.

Questionnaires were administered online via EvaSys survey tool, and the data were automatically transferred to SPSS for computation.

\subsection{Instruments}

For collecting quantitative data, various five-point Likert-type scales ranging from 0 (=not at all true) to 4 (=extremely true) were used. The self-report questionnaire comprised 56 items. To measure engagement, the subscales narrative presence (NP 1-3) and emotional engagement (EE 1-3) from the Narrative Engagement Scale (Busselle \& Bilandzic, 2009) were applied. 23 Items measuring integrative comprehension (INC 1-13) and expressive enactment (EXE 1-10) from the Absorption-Like States Questionnaire (ASQ; Kuiken \& Douglas, 2017) were added. Moreover, participants responded to the empathy (EMP 1-7) subscale from the Literary Response Questionnaire (LRQ; Miall \& Kuiken, 1995).

To measure self-insights, two standardized instruments were applied: the Insight subscale (INS 1-13) from the LRQ and the self-perceptual depth subscale (SPD 1-7) from the Experiencing Questionnaire (EQ; Kuiken, Campbell \& Sopcak, 2012).

\subsection{Data analysis} analysis.

In this study, the underlying structure of the instrument was explored using exploratory factor

Although the structure of the subscales had been previously established using EFA, it was not appropriate to only use CFA because the subscales were newly combined to address the need for an instrument that assesses pedagogical interventions, thus potentially changing the latent structure of the data. EFA was performed on the full sample using SPSS version 26 after having confirmed that the assumptions for factor analysis were met and the data were suitable for this statistical procedure. Principal axis factoring was used to extract the factors because Tabachnick and Fidell suggest applying PAF instead of PCA when the researcher is interested in a "theoretical solution uncontaminated by unique and error variability and [researchers] have designed [their] study on the basis of underlying constructs that are expected to produce scores on [their] observed variables". $(2007,63)$. This was followed by oblique rotation of factors using Promax rotation.

The decision on the number of factors to be retained was guided by three statistical criteria: 1. Kaiser's criterion of eigenvalues above $1^{1}, 2$. inspection of the screeplot, and 3. PCA parallel analysis using the software developed by Watkins. Items with low communalities or high cross-loadings (above .32) were dropped from the initial solution. We adopted the suggestion that "if the cutoff for the number of factors is unclear, the researcher might find it useful to undertake several factor analyses with different numbers of specified factors." (Pett, Lackey \& Sullivan, 2003, 120). In addition to the statistical criteria, factor interpretability and usefulness of the solution (s.a.) were taken into account when deciding on the number of factors to be retained.

\footnotetext{
${ }^{1}$ Gorsuch (1983) suggests that this criterion is most accurate when there are fewer than 40 variables, the sample size is large, and the number of factors is expected to be between [n of variables/5] and [ $\mathrm{n}$ of variables/3]. Only one condition is met in our case as the instrument comprises 56 items and the number of expected factors is smaller than $n$ of variables $/ 5$. As a result, this criterion must be applied with caution.
} 
After having established the measurement model by means of EFA, the reliability of the subscales was assessed using Cronbach alpha coefficients.

\section{Results}

\subsection{Suitability of the data}

The Kaiser-Meyer-Olkin (.940) and Bartlett test of sphericity (.000) indicated that the data were adequate for factorization. According to Tabachnick and Fidell (2007), the sample size of 417 can be considered as good. A missing data (pairwise) correlation matrix was analysed. From the inspection of P-P plots for each variable, we can infer that the data were, overall, normally distributed. Mahalanobis Distance analysis with a cutoff level of $\alpha=.001$ detected 16 multivariate outliers. These cases were excluded from the subsequent principal factors extraction.

\subsection{Factor analysis}

Principal axis factoring (PAF) with Promax rotation was performed through SPSS 26 on 56 items for a sample of 401 students. Principal components extraction was used prior to principal axis factoring to estimate the number of factors and absence of multicollinearity. PAF revealed ten eigenvalues exceeding 1 (54.686\% of the total variance explained), but only five factors exceeded the criterion value obtained from Parallel Analysis (Horn, 1965). Inspection of the scree plot (Cattell, 1966) supported a five factor solution (47.350 \% of the total variance explained). Therefore, the number of factors to retain is ambiguous.

Due to low communalities, items INS $12(.122)$ and INS $13(.217)$ were excluded. Factors 9 (EE 2 and 3) and 10 (INC 2 and 3) were deleted because only two items loaded on these latent variables and eigenvalues for factors 9 and 10 were low. In addition, cross-loadings were above .32 for items INC 2 and 3 .

Thus, 50 items qualified for further analysis. PAF with oblique rotation of the variables was rerun and yielded 8 factors with eigenvalues exceeding 1, accounting for 53,752 per cent of the total variance explained. Inspection of the Pattern Matrix showed a relatively clear eight factor solution in line with the theoretical background provided by the authors of the instruments.

As statistical and theoretical criteria yielded different results on how many factors to retain, PAF was rerun with 5, 6, 7, and 8 specified factors. The 8 factor solution proved the most adequate fit. The Pattern Matrix displayed a clear structure (Table 1, Cf. appendix). Moreover, this solution is in line with the theoretical underpinning of the given instruments. Finally, it serves the research purpose of validating a measure that is capable of assessing shifts in both self-insight and transactional modes of engagement. In a five factor solution, the modes "Pre-enactive Empathy", "Realism" and "Self-implicating Givenness" which are crucial to evaluating the efficacy of pedagogic interventions in the field of literature education were lost.

To enhance the interpretability of the factors, only variables with factor loadings as follows were selected for inclusion in their respective factors: $>.55$ (factor 1), >.75 (factor 2), >.61 (factor 3 ), .58 (factor 4), .75 (factor 5), >.52 (factor 6), >.59 (factor 7), >.60 (factor 8). Therefore, the following items were deleted: EE1, EMP 1, EXE 1, EXE 2, EXE 3, INS 1, INS 2, INS 10, INC 1, INC 8, INC 9, INC 11, SPD 6, SPD 7.

In accordance with the original labels of the standardized instruments, the factors are named, respectively: (i) Insight; (ii) Cognitive Perspective-taking; (iii) Self-perceptual Depth; (iv) Identification ${ }^{2}$; (v) Narrative Presence; (vi) Pre-enactive Empathy; (vii) Realism; (viii) Self-implicating Givenness.

Following Promax rotation, the 8 factors showed moderate intercorrelations $(r=.14-.65)$.

\subsection{Reliability}

The Cronbach alpha values for the subscales generated by PAF exceeded the recommended value of .7, indicating adequate internal consistency (Table 2).

Table 1. Descriptive statistics and reliability of subscales.

\begin{tabular}{|c|c|c|c|c|}
\hline \multirow{2}{*}{ Subscales } & \multirow{2}{*}{ No. items } & \multicolumn{2}{|c|}{ Students' Ratings } & \multirow{2}{*}{$\begin{array}{l}\text { Internal consistency } \\
\text { Cronbach's alpha }\end{array}$} \\
\hline & & $M$ & S.D. & \\
\hline Insight & 8 & 1.85 & .83 & .86 \\
\hline Cognitive Perspective-taking & 4 & 2.54 & .96 & .87 \\
\hline Self-perceptual Depth & 5 & 1.09 & .83 & .86 \\
\hline Identification & 6 & 1.35 & .91 & .80 \\
\hline Narrative Presence & 3 & 1.87 & 1.07 & .81 \\
\hline Pre-enactive Empathy & 4 & 1.02 & .99 & .86 \\
\hline Realism & 3 & 1.77 & .93 & .80 \\
\hline Self-implicating givenness & 3 & 1.27 & 1.05 & .86 \\
\hline
\end{tabular}

\footnotetext{
${ }^{2}$ Factor 4 was renamed from "Empathy" (LRQ) to "Identification" in order to guarantee discrimination between factors 4 and 6 which measure different aspects of the relationship between reader and character.
} 


\section{Discussion and conclusions}

This study yielded an instrument with valid and reliable scores that can assess high school students' engagement and self-insights. Eight dimensions of reading experience were extracted. The factors Insight and Selp-perceptual depth are considered to be forms of self-insight, the factors Cognitive Perspective-taking, Identification, Narrative Presence, Pre-enactive Empathy, Realism, and Self-implicating Givenness constitute interrelated modes of engagement. The eight factors are investigated on the respective subscales which all show a satisfactory internal consistency ( $\alpha>0.80$ for all subscales).

It has to be noted that confirmatory factor analysis needs to be performed in order to assess the fit of the proposed measurement model. A structural model has to be added to understand possible predictors of self-insight.

Furthermore, reading experience is dependent on the literary text assigned for reading and on the students involved. Therefore, the study has to be replicated with different materials and populations.

It must be considered a limitation of the study that three of the proposed modes of engagement (Emotional Engagement, Peri-personal Space, Extra-personal Space) had to be excluded due to statistical reason. Further research has to cover alternative modes of engagement with literary texts.

Finally, upcoming research projects should take other variables into account that might influence students' responses to literature (e.g. reading habits, reading motivation, personal bias, attitudes to teachers).

In conclusion it can be said that instructional interventions need to be empirically researched in order to test their learning effects on students. The proposed eight-factor instrument might serve as a valid and reliable measure of students' engagement and self-insight.

\section{References}

Andringa, E. (1996). Effects of 'narrative distance' on readers' emotional involvement and response. Poetics, 23(6), 431-452.

Busselle, R. \& Bilandzic, H. (2009). Measuring Narrative Engagement. Media Psychology, 12(4), 321-347.

Cattell, R. B. (1966). The scree test for the numbers of factors. Multivariate Behavioral Research, 1, 245-276.

Fialho, O., Zyngier, S. \& Burke, Michael (2016). Empirical approaches to the study of literature in learning environments: An overview. In M. Burke, O. Fialho, \& S. Zyngier (Eds.), Scientific Approaches to Literature in Learning Environments (pp. 1-16). Amsterdam: John Benjamins.

Fialho, O., Zyngier, S. \& Miall, C. (2011). Interpretation and experience: Two pedagogical interventions observed. English in Education, 45(3), 236-253.

Gorsuch, R. (1983). Factor analysis. $2^{\text {nd }}$ ed. Hillsdale, NJ: Lawrence Erlbaum Associates.

Horn, J.L. (1965). A rationale and test for the number of factors in factor analysis. Psychometrika, 30, $179-185$.

Janssen, T. \& Rijlaarsdam, G. (1995). Approaches to the teaching of literature: A national survey of literary education in Dutch secondary schools. In R.J. Kreuz \& M.S. MacNealy (Eds.), Empirical approaches to literature and aesthetics (pp. 513-536). Norwood, NJ: Ablex.

Janssen, T., Braaksma, M. Rijlaarsdem, M. \& van den Bergh, H. (2012). Flexibility in reading literature. Differences between good and poor adolescent readers. Scientific Study of Literature, 2(1), 83-107.

Kuiken, D. \& Douglas, Sh. (2017). Forms of absorption that facilitate the aesthetic and explanatory effects of literary reading. In F. Hakemulder, M. M. Kuijpers, E. S. Tan, K. Bálint \& M. M. Doicaru (Eds.), Narrative absorption (pp. 217-249). Amsterdam: John Benjamins.

Kuiken, D., Campbell, P. \& Sopcak, P. (2012). The Experiencing Questionnaire: Locating exceptional reading moments. Scientific Study of Literature, 2(2), 243-272.

Miall, D. \& Kuiken, D. (1995). Aspects of literary response: A new questionnaire. Research in the Teaching of English, 29. 37-58.

Miall, D. (2006). Literary reading: Empirical and theoretical studies. New York: Peter Lang Publishing.

Miall, D. (2011). Science in the perspective of literariness. Scientific Study of Literature, 1, 7-14.

Pallant, J. (2011). SPSS survival manual: A step by step guide to data analysis using SPSS. $4^{\text {th }}$ ed. Crows Nest: Allen \& Unwin.

Peskin, J. (2010). The development of poetic literacy through the school years. Discourse Processes, 47, 77-103.

Pett, M.A., Lackey, N.R. \& Sullivan, J.J. (2003). Making sense of factor analysis. Thousand Oaks: Sage.

Shrijvers, M., Janssen, T., Fialho, O., De Maeyer, S., Rijlaarsdam, G. (2019). Transformative Dialogic Literature Teaching fosters adolescents ' insight into human nature and motivation. Learning and Instruction, 63, 1-15. 
Tabachnick, B.J \& Fidell, L.S. (2007). Using multivariate statistics. $5^{\text {th }}$ ed. Boston: Pearson.

Van Schooten, E. \& Glopper, K. (2003). The development of literary response in secondary education. Poetics, 31, 155-187.

Van Schooten, E., Ootsdam, R. \& de Glopper, K. (2001). Dimensions and predictors of literary response. Journal of Literacy Research, 33(1), 1-32.

\section{Appendix}

Table 1. Pattern Matrix and Communalities for PAF with Promax Variation.

\begin{tabular}{|c|c|c|c|c|c|c|c|c|c|}
\hline \multirow{2}{*}{ Items } & \multicolumn{8}{|l|}{ Factors } & \multirow{2}{*}{$\mathrm{COM}$} \\
\hline & 1 & 2 & 3 & 4 & 5 & 6 & 7 & 8 & \\
\hline INS4 & .817 & .056 & .074 & -.112 & -.143 & .065 & .015 & -.110 & .575 \\
\hline INS7 & .722 & -.156 & -.162 & .000 & .050 & .071 & -.002 & .182 & .510 \\
\hline INS5 & .721 & .088 & .093 & .029 & -.114 & .057 & -.075 & -.088 & .569 \\
\hline INS3 & .687 & .047 & -.110 & -.079 & .078 & -.152 & -.044 & .217 & .468 \\
\hline INS9 & .623 & -.038 & .146 & .034 & -.198 & .123 & .137 & -.188 & .441 \\
\hline INS8 & .619 & -.030 & .180 & .045 & -.026 & -.081 & .126 & -.114 & .485 \\
\hline INS6 & .598 & -.144 & -.164 & -.022 & .240 & -.058 & .024 & .170 & .411 \\
\hline INS11 & .551 & -.070 & -.147 & .046 & .051 & .088 & .049 & .186 & .414 \\
\hline INC6 & .005 & .850 & -.008 & -.019 & -.068 & -.090 & .005 & .125 & .651 \\
\hline INC7 & -.040 & .823 & -.121 & -.056 & .075 & -.021 & -.049 & .142 & .645 \\
\hline INC5 & .036 & .779 & .003 & .045 & -.106 & -.018 & .002 & .077 & .589 \\
\hline INC4 & .039 & .754 & -.012 & .055 & .028 & .012 & -.057 & -.069 & .593 \\
\hline SPD3 & -.030 & -.036 & .867 & .118 & -.180 & .045 & -.057 & .000 & .621 \\
\hline SPD4 & .056 & .060 & .714 & -.133 & .079 & .011 & .033 & -.029 & .619 \\
\hline SPD2 & .007 & -.169 & .706 & -.020 & -.024 & -.018 & .043 & .171 & .522 \\
\hline SPD5 & .035 & .069 & .664 & -.042 & -.033 & .089 & .004 & .002 & .539 \\
\hline SPD1 & .096 & -.082 & .619 & .001 & .131 & -.034 & .020 & .142 & .618 \\
\hline EMP5 & -.035 & -.005 & -.041 & .720 & .013 & -.072 & .128 & .025 & .476 \\
\hline EMP3 & .029 & .122 & -.167 & .621 & -.044 & .090 & .020 & .109 & .493 \\
\hline EMP4 & -.129 & -.155 & .146 & .620 & .031 & -.168 & .042 & .122 & .327 \\
\hline EMP7 & -.003 & .182 & .041 & .614 & .085 & -.078 & -.049 & -.044 & .493 \\
\hline EMP2 & .055 & .014 & -.109 & .605 & -.041 & .090 & -.067 & .049 & .413 \\
\hline EMP6 & .066 & -.160 & .115 & .583 & -.016 & .053 & .030 & -.043 & .404 \\
\hline NP3 & -.049 & -.135 & .007 & -.018 & .857 & .069 & .101 & -.083 & .629 \\
\hline NP1 & .049 & .096 & -.143 & .039 & .759 & -.015 & -.016 & -.109 & .538 \\
\hline NP2 & .001 & -.004 & .002 & .000 & .759 & .037 & .037 & -.173 & .529 \\
\hline EXE5 & .028 & -.075 & -.064 & -.027 & .052 & .841 & -.021 & .181 & .796 \\
\hline EXE4 & .029 & -.109 & -.030 & -.099 & .005 & .759 & .163 & .054 & .573 \\
\hline EXE6 & -.074 & .052 & .125 & -.021 & .154 & .544 & -.023 & .090 & .580 \\
\hline EXE7 & -.030 & .035 & .149 & .074 & -.042 & .523 & -.036 & .191 & .537 \\
\hline INC12 & .054 & .173 & -.041 & .065 & -.001 & .009 & .721 & -.064 & .656 \\
\hline INC13 & -.038 & -.106 & .001 & .083 & .025 & .104 & .707 & .096 & .589 \\
\hline INC10 & .056 & .052 & .060 & -.064 & .025 & -.018 & .598 & .161 & .560 \\
\hline EXE9 & -.030 & .135 & .109 & .049 & -.169 & .095 & .037 & .719 & .675 \\
\hline EXE8 & .008 & .095 & .106 & .091 & -.170 & .097 & .013 & .705 & .651 \\
\hline EXE10 & -.027 & .052 & .075 & .003 & -.126 & .263 & .050 & .606 & .600 \\
\hline
\end{tabular}

Note. Factor $1=$ Insight. Factor $2=$ Cognitive Perspective-Taking. Factor $3=$ Self-perceptual depth. Factor $4=$ Identification. Factor 5 =Narrative Presence. Factor $6=$ Pre-enactive Empathy. Factor $7=$ Realism. Factor $8=$ Self-implicating Givenness. COM = communalities.

Bolded items indicate major loadings for each item. 